\title{
Oxygen saturation in adults with acute asthma
}

\author{
Richard Hardern
}

\begin{abstract}
Avoidable deaths from asthma continue. Some of these result from the difficulty in determining the severity of an acute asthma attack at the initial assessment. This study evaluated the relation of pulse oximetry with other markers of severity in 46 patients attending an accident and emergency (A\&E) department with acute asthma. Neither oxygen saturation nor peak flow correlated with length of admission or with other "retrospective" markers of severity. Attempts to collect follow up data (for example, peak flow charts) from patients discharged from the A\&E department failed. It proved impossible to determine whether pulse oximetry predicts which adults can be discharged.

( $\mathcal{F}$ Accid Emerg Med 1996;13:28-30)
\end{abstract}

Key terms: asthma; oxygen saturation; peak flow.

Asthma mortality is increasing. ${ }^{1-3}$ Avoidable deaths continue, even in hospital. ${ }^{4}$ Current methods of evaluation do not accurately identify patients at risk of sudden death or respiratory arrest": "Physicians practising in emergency departments have great difficulty in predicting whether a given patient should be admitted or whether he or she can be treated and discharged from the emergency department without early relapse". ${ }^{6}$

Current guidelines on the management of acute asthma are based on the peak flow measurements and on clinical features (heart rate and respiratory rate).$^{7-9}$ Oxygen saturation on presentation helps predict the need for admission of children with asthma. ${ }^{10}$ The aims of this study (at its outset) were to assess whether pulse oximetry is as helpful in adults, and to determine whether oxygen saturation is related to other variables.

\section{Methods}

Forty six consecutive patients attending an accident and emergency (A\&E) department with acute asthma of sufficient severity to warrant treatment with nebulised drugs were prospectively enrolled into the study on presentation. Exclusion criteria were age less than 16 years and breathlessness from other causes (such as chronic obstructive lung disease).

On arrival the peak flow and oxygen saturation were determined. A Wright minipeak flow meter was used to determine the peak flow rate (taking the highest of three attempts). The arterial oxygen saturation was measured using a Dalex pulse oximeter and finger probe (with the patient breathing air); the value was noted when stable and when the heart rate shown on the oximeter was the same as the palpable pulse rate. The patient then received nebulised treatment. The delay in providing treatment was minimal. Measurements were repeated 30 min after drug delivery was completed. The predicted peak flow of each patient was estimated from their age, height, and sex. ${ }^{11}$

It was difficult to identify "inpatient" outcome measures that reflect the severity of episodes of acute asthma. Death and the need for ventilation are the "hardest" measures, but are too infrequent to be useful in studies of this size. The alternatives chosen were: length of admission, duration of treatment with nebulised bronchodilators, time taken for the peak flow to reach $80 \%$ of the predicted value, and time taken for the diurnal variation in peak flow to fall below $20 \%$. Although these all depend, at least in part, on peak flow measurements, superior outcomes could not be $\vec{\theta}$ identified. These data were extracted from the hospital case notes of patients who had been admitted.

The study was approved by the hospital ethics committee. Correlations were determined using Pearson product-moment coefficients $(r)$

\section{Results}

Data were obtained from 46 patients, of whom 27 (59\%) were admitted. Baseline peak expiratory flow rate and oxygen saturation are shown in tables 1 and 2. The mean heart rate was 102 beats $\cdot \mathrm{min}^{-1}$ and the mean respiratory rate $27 \cdot \mathrm{min}^{-1}$. As one would expect if guidelines current at that time ${ }^{7}$ had been followed, there was little overlap in peak flow between patients discharged from $\mathrm{A} \& \mathrm{E}$ and those admitted. From oxygen saturation measurements, the distinction between these groups of patients was not clear.

Patients with oxygen saturation of $91 \%$ or $N$ less (the cut off value used by Geelhoed et $a l^{10}$ )

Table 1 Percentage of predicted peak expiratory flow rate; mean $(95 \% C I)$.

\begin{tabular}{lll}
\hline & On arrival & After treatment \\
\hline Overall & $40(34-45)$ & $53(46-60)$ \\
Admitted & $33(26-40)$ & $42(34-49)$ \\
Discharged & $50(42-58)$ & $72(65-79)$ \\
\hline
\end{tabular}

Table 2 Oxygen saturation $\left(\mathrm{FiO}_{2}=0 \cdot 21\right)$, mean $(95 \% \mathrm{CI})$

\begin{tabular}{lll}
\hline & On arrival & After treatment \\
\hline Overall & $92 \cdot 5(89 \cdot 2-95 \cdot 8)$ & $96 \cdot 3(95 \cdot 7-96 \cdot 9)$ \\
Admitted & $90 \cdot 5(85 \cdot 3-95 \cdot 7)$ & $95 \cdot 7(94 \cdot 9-96 \cdot 5)$ \\
Discharged & $95 \cdot 3(93 \cdot 7-96 \cdot 9)$ & $97 \cdot 1(96 \cdot 3-97 \cdot 9)$ \\
\hline
\end{tabular} \\ Accident and \\ R Hardern, Senior House \\ Correspondence to:
}


Table 3 Correlations between clinical findings, percentage of predicted peak expiratory flow rate, and oxygen saturation; r (Pvalue).

\begin{tabular}{lll}
\hline & Heart rate & Respiratory rate \\
\hline Pre-treatment saturation & -0.199 & +0.176 \\
& $(0.225)$ & $(0.370)$ \\
Post-treatment saturation & -0.060 & +0.072 \\
& $(0.732)$ & $(0.733)$ \\
Pre-treatment \% PPF & -0.409 & -0.325 \\
& $(0.007)$ & $(0.074)$ \\
Post-treatment \% PPF & -0.476 & -0.379 \\
& $(0.002)$ & $(0.043)$ \\
\hline
\end{tabular}

$\% \mathrm{PPF}=$ percent of predicted peak flow.

were not significantly less likely to be discharged [two of eight patients in this group were discharged: $95 \%$ confidence interval (CI) $3 \cdot 2-65 \cdot 1 \%$ ] than those with higher values [11 of 33: $95 \%$ CI $18 \cdot 0$ to $51 \cdot 8 \%$ ]. The initial oxygen saturation of five patients, one of whom was admitted, was not recorded. It was not clear whether two patients, both with an initial oxygen saturation $>91 \%$, were admitted or discharged.

The mean initial heart rate was 108 beats $\cdot \mathrm{min}^{-1}$ among patients with initial oxygen saturation of $91 \%$ or less, and 102 in the other patients (NS). The mean values of respiratory rate and of the "retrospective variables" were higher (suggesting more severe asthma) in the group with an oxygen saturation of $91 \%$ and below (all between group comparisons were non-significant).

No correlation was found between oxygen saturation and heart rate or respiratory rate. There was a significant correlation between initial heart rate and peak flow (before and after treatment, $P=0.007$ and $P=0.002$ respectively) (table 3.)

Table 4 shows the correlation between the "presentation variables" (heart rate, respiratory rate, oxygen saturation, and per cent predicted peak flow rate) and "retrospective variables" (length of hospital admission, duration of nebuliser treatment, time taken for the peak flow to reach $80 \%$ of the expected peak flow, and time taken for the diurnal variation in peak flow to fall below $20 \%$ ). The clinical finding at presentation most strongly associated with length of admission was the respiratory rate, though this did not reach statistical significance $(P=0 \cdot 140)$. The initial respiratory rate was the variable most strongly associated (again non-significantly) with the duration of nebuliser treatment, with the time taken for the peak flow to reach $80 \%$ of the

Table 4 Correlations between variables measured on arrival and those measured after admission (data from admitted patients only); r (P value).

\begin{tabular}{lcccc}
\hline & Length & Nebuliser & $P F>80$ & $D V<20$ \\
\hline Pretreatment saturation & +0.006 & +0.067 & +0.195 & +0.123 \\
& $(0.978)$ & $(0.756)$ & $(0.410)$ & $(0.661)$ \\
Post-treatment saturation & -0.071 & -0.053 & +0.018 & -0.033 \\
& $(0.761)$ & $(0.821)$ & $(0.943)$ & $(0.916)$ \\
Pretreatment \% PPF & -0.152 & -0.104 & -0.251 & +0.134 \\
& $(0.470)$ & $(0.622)$ & $(0.273)$ & $(0.619)$ \\
Post-treatment \% PPF & -0.175 & -0.120 & -0.217 & +0.0003 \\
& $(0.412)$ & $(0.575)$ & $(0.345)$ & $(0.999)$ \\
Heart rate & +0.175 & +0.161 & +0.207 & +0.061 \\
& $(0.393)$ & $(0.432)$ & $(0.355)$ & $(0.815)$ \\
Respiratory rate & +0.352 & +0.299 & +0.400 & -0.228 \\
& $(0.140)$ & $(0.214)$ & $(0.125)$ & $(0.454)$ \\
\hline
\end{tabular}

Length = length of admission; Nebuliser $=$ duration of nebulised treatment; $\mathrm{PF}>80=$ time for peak flow to reach $80 \%$ predicted value; $\mathrm{DV}<20=$ time for diurnal variation in peak flow to fall below $20 \%$. expected value, and with the time taken for the diurnal variation in peak flow to fall below $20 \%$. Neither peak flow values nor oxygen saturation values were correlated significantly with any of the retrospective variables.

\section{Discussion}

These data provide new information about the relations between oxygen saturation and other variables in adults with acute asthma. Unfortunately they do not help to predict which patients can be discharged. Because it proved impossible to collect follow up data from patients discharged from $A \& E$, it was not possible to assess the performance of pulse oximetry at predicting which patients required admission and which could safely continue treatment at home.

The patients in this study were comparable (as assessed by peak flow) with those attending A\&E departments elsewhere in the United Kingdom. ${ }^{12}$ A study with aims similar to ours has recently been reported. ${ }^{13}$ This found a nonsignificant trend for lower oxygen saturation to be associated with the need for hospital admission. It was not clear what criteria were used to decide if admission were needed (only 14 of 276 were admitted). Discharged patients were not followed up. One cannot justify a change in clinical practice with these data.

The ideal tool to aid in deciding whether to admit a patient would not only be accurate but would also use indices that can be quickly and easily measured (if not, it would not be practical for $A \& E$ use). An index has been devised which uses clinical findings, but this was unreliable when prospectively evaluated. ${ }^{6}$

Peak flow is thought to be more accurate than clinical assessment in determining the severity of acute asthma (unless there are signs of life threatening asthma such as cyanosis); symptoms and signs disappear despite continuing spirometric impairment. ${ }^{14}$ Peak flow, however, provides only an approximate guide to the severity of acute asthma. Gas exchange abnormalities, mainly the result of small airway pathology or ventilation/perfusion mismatch, cannot be inferred from the degree of impairment in air flow rates, which reflect large airway calibre. ${ }^{15} 16$ Arterial oxygen saturation determination by pulse oximetry is easily carried out, comfortable, and non-invasive. ${ }^{17-20}$ When used to monitor patients with respiratory distress, a close correlation between oximetric and measured saturation was found. ${ }^{18}$ Further studies examining the role of oximetry may yield useful results. One potential avenue is the evaluation of the role of serial assessments of oxygen saturation.

Reliable "retrospective" measures of severity are needed. Death or the need for ventilation are too rare to be used in single centre studies; other measures are needed as "surrogates" in such studies.

The decision whether to admit a patient with asthma is one that all $\mathrm{A} \& \mathrm{E}$ staff have to make often. Improving the accuracy of these decisions should remain a priority of emergency medicine research; inaccuracy may lead to unnecessary admission or unnecessary death. 
I should like to acknowledge Dr W Yeo, who brought to my attention the paper of Geelhoed et al and provided the origina idea of carrying out the study, and Dr J Cooper for statistical analysis.

1 Mitchell EA. Is current treatment increasing asthma mortality and morbidity? Thorax $1989 ; 44: 81-4$.

2 Burney PGJ. Asthma mortality in England and Wales: evidence for a further increase 1974-1984. Lancet 1986;ii:323.

3 Burney PGJ. Asthma: evidence for a rising prevalence. Proc $R$ Coll Physicians Edinb 1993;23:595-600.

4 Eason J, Markowe HJL. Controlled investigation of death from asthma in hospitals in the North East Thames region. $B M F$ 1987;294:1255-8.

5 Hetzel MR, Clark TJH, Branthwaite MA. (1977) Asthma analysis of sudden deaths and ventilatory arrests in hospital. British Medical Journal i, 808-811.

6 Rose CC, Murphy JG, Schwartz JS. Performance of an index predicting the response of patients with acute bronchial asthma to intensive emergency department treatment. $N$ Engl $\mathcal{Y}$ Med 1984;340:573-7.

7 British Thoracic Society, Research Unit of the Royal College of Physicians, King's Fund Centre, National Asthma Campaign. Guidelines for management of asthma in adults. II. Acute severe asthma. BMf 1990;301: asthma

8 British Thoracic Society, British Paediatric Association, Research Unit at the Royal College of Physicians of London, King's Fund Centre, National Asthma Campaign, Royal College of General Practitioners, General Practitioners in Asthma Group, British Association of Accident and Emergency Medicine, British Paediatric Respiratory Group. Guidelines for the management of asthma: a summary. BMF 1993;306:776-82 (with corrections to chart 6 in $B M F$ 307:1054).

9 US Department of Health and Human Services. International consensus report on diagnosis and management of asthma. Bethesda, Maryland: National Heart, Lung and Blood Institute, 1992. (Publication No 92-3091.)
10 Geelhoed GC, Landau LI, LeSouef PN. Predicted value of oxygen saturation in emergency evaluation of asthmatic children. $B M f$ 1988;297:395-6.

11 Nunn AJ, Gregg I. New regression equations for predicting a peak expiratory flow in adults. $B M F$ 1989;298: 1068.

12 Chidley KE, Wood-Baker R, Town GI, Sleet RA, Holgate ST. Reassessment of asthma management in an accident and emergency department. Resp Med 1991;85: 373-7.

13 Murphy DG, Halloran $K$, Rydman $R$, Ahrens W. Initial pulse oximetry as a predictor of outcome among adult acute asthmatics treated in an emergency department observation unit [abstr]. Ann Emerg Med 1995;25: $156-7$

14 McFadden ER, Kiser R, De Groot WJ. Acute bronchial asthma: relationships between clinical and physiological manifestations. N Engl f Med 1973;288:221-5.

15 Roca J, Ramis LI, Rodriguez-Roisin R, Ballester E, Motserrat JM, Wagner PD. Serial relationships between the ventilation-effusion in equality and spirometry in acute severe asthma requiring hospitalisation. $\mathrm{Am} R e v$ Resp Dis 1988;137:1055-61.

16 Rudolf M, Riordan JF, Grant BJB, Maberly DJ, Saunders KB. Arterial blood gas tensions in acute severe asthma, Eur 7 Clin Invest 1980;10:55-62.

17 Galdun JP, Paris PM, Stewart RD. Pulse oximetry in the emergency department. Am 7 Emerg Med 1989;7: $422-5$.

18 Jones J, Heiselman D, Cannon L, Gradisek R. Continuous emergency department monitoring of arterial saturation in adult patients with respiratory distress. Ann Emerg Med 1988;17:463-8.

19 Lambert MA, Crinnion J. The role of pulse oximetry in the accident and emergency department. Arch Emerg Med 1989;6:211-5.

20 Kellerman AL, Cofer CA, Joseph S, Hackman EB. Impact of portable pulse oximetry on arterial blood gas test ordering in urban emergency department. Ann Emerg Med 1991;20:130-4.

\section{Injury Research Group}

The 1996 annual meeting will be held in Manchester on 1-2 April. There will be a session of free communications and symposia on wound healing and on the psychological and psychiatric consequences of trauma. For details please contact:

Dr R N Barton

North Western Injury Research Centre

Stopford Building

University of Manchester

Oxford Road

Manchester M13 9PT

(Telephone 0161-275 5188, fax 0161-275 5190) 